\title{
Correlates of Obsessive-Compulsive Disorder in a Sample of HIV-Positive, Methamphetamine-using Men Who have Sex with Men
}

\author{
Shirley J. Semple $\cdot$ Steffanie A. Strathdee • \\ Jim Zians · John McQuaid · Thomas L. Patterson
}

Published online: 8 June 2010

(c) The Author(s) 2010. This article is published with open access at Springerlink.com

\begin{abstract}
Substance use has been identified as a risk factor for elevated levels of obsessive-compulsive disorder (OCD). This study examined methamphetamine use and sexual risk behaviors as correlates of OCD in a sample of 245 HIV-positive men having sex with men (MSM) in San Diego, CA. In a logistic regression analysis, OCD was associated with greater frequency of methamphetamine use, more depressive symptoms, seeking out risky venues and risky sexual partners when "high" on methamphetamine, and reporting fewer sex acts in the past 2 months. These data suggest the need for increased awareness and understanding of the role that OCD may play in the drug use behaviors and risky sexual practices of methamphetamine users.
\end{abstract}

Keywords Obsessive-compulsive disorder .

Methamphetamine - Sexual risk behavior .

Men who have sex with men · HIV

S. J. Semple · J. Zians · T. L. Patterson $(\bowtie)$

Department of Psychiatry (0680), University of California, San

Diego, 9500 Gilman Drive, La Jolla, CA 92093-0680, USA

e-mail: tpatterson@ucsd.edu

\section{S. A. Strathdee}

Division of Global Public Health, Department of Medicine,

University of California, San Diego, La Jolla, CA, USA

J. McQuaid

Department of Veterans Affairs Medical Center,

San Francisco, CA, USA

\section{Introduction}

Previous research has shown that substance use disorders (SUDs) are linked to a variety of co-morbid conditions, including obsessive-compulsive disorder (OCD) [1, 2]. The prevalence of OCD among methamphetamine users and the link between patterns of methamphetamine use and OCD have not been studied. Moreover, there is little information on the relationship between OCD and high-risk sexual behaviors, which are common among methamphetamine users $[3,4]$. We propose that successful treatment of individuals with OCD and methamphetamine use disorder may require addressing both conditions. To this end, it is important to identify behaviors and conditions that are associated with methamphetamine use and OCD comorbidity. The present study examines substance use patterns and sexual risk behaviors as correlates of OCD in a high-risk and high-need population of HIV-positive methamphetamine-using men who have sex with men (MSM).

Examining patterns of methamphetamine use, above and beyond SUD diagnosis, may improve our understanding of the links between OCD and SUDs. Although we were unable to find studies that link frequency of drug use or binge drug use to OCD, several studies have documented a positive relationship between binge eating and OCD [5, 6]. Given that binge eating can have similar patterns to drug use by those with SUD [7], a similar relationship may be present between OCD and SUD.

There is a lack of studies that report on the sexual risk behaviors of SUD patients with OCD comorbidity. However, in one study of non-substance users, the severity of OCD symptoms was negatively correlated with relationship intimacy, relationship satisfaction, and self-disclosure of the disorder. Severity of OCD symptoms was also positively associated with fears regarding contamination 
from sexual activity [8]. In another study, $24.9 \%$ of OCD patients meeting DSM-IV criteria reported a history of sexual obsessions [9], suggesting that this is a fairly common clinical feature of OCD.

In the general population, depressive disorders are common among OCD patients [10]. McElroy et al. [11] have suggested that OCD spectrum disorders belong to the broader family of affective orders. In a study of axis I comorbidity in OCD, major depression (MDD) was identified as the most common comorbidity, with $39.5 \%$ of OCD patients presenting with MDD [12]. In another study that examined the co-occurrence of depressive disorders in OCD, one-third of the sample was diagnosed with comorbid depression [13]. Moreover, studies that compared OCD patients who have major depression with those who do not have found significant differences in the presentation and clinical severity of symptoms [10, 14, 15], suggesting the need to include a measure of depression in studies of obsessive-compulsive disorders.

Studies that have examined risk factors and correlates of obsessive-compulsive disorder have found few associations with demographic characteristics [16, 17]. OCD symptoms typically begin before the age of 30 , but cases with later onset have been documented [18]. The onset of symptoms tends to be gradual, and their development is continuous regardless of age of onset [19]. In an epidemiological study, OCD was found to affect mostly female adults and male children and adolescents. Individuals who were unmarried and abused drugs were also more likely to have OCD symptoms [17].

The purpose of the current study is twofold: first, to examine the prevalence of OCD in a sample of HIVpositive, methamphetamine-using MSM, and second, to identify behavioral correlates of OCD in this target population. We hypothesized that methamphetamine use and risky sexual behaviors would be associated with clinical levels of OCD symptoms as measured by the Obsessive Compulsive Inventory, Revised (OCI-R) [20].

\section{Methods}

\section{Sample Selection}

These analyses used baseline data from a sample of 245 men who were enrolled in a long-term efficacy study of a sexual risk reduction intervention for HIV-positive, methamphetamine-using MSM. The protocol entailed five individual counseling sessions and eight group-based maintenance sessions that used motivational interviewing [21], social cognitive strategies [22], and cognitive behavioral therapy [23] to reduce high-risk sexual practices and maintain treatment effects. Eligible participants were at least 18 years of age, self-identified as MSM, and reported having had unprotected anal sex with at least one same-sex partner during the previous 2 months. To avoid the enrollment of one-time users of this drug, it was also required that participants have used methamphetamine at least twice during the past 2 months, and at least once during the past 30 days. Recruitment sources included community-based service providers, poster and media campaigns, street outreach, and referrals from enrolled participants. Interviews were conducted using audio-CASI technology [24].

Measures

\section{Obsessive-Compulsive Symptoms}

To assess severity of OCD symptoms, we used the Obsessive Compulsive Inventory Revised (OCI-R), which consists of 18 items with six subscales. The subscales include: washing, checking, ordering, obsessing, hoarding, and neutralizing. Participants are asked to rate each item in terms of how much they were bothered or distressed by a specific experience. Sample items include: During the past month, the following experience has bothered or distressed me: (a) I have saved up so many things that they get in the way (hoarding); (b) I check things more often than necessary (checking); and (c) I am compelled to count while doing things (neutralizing). Items are rated on a 4-point scale ranging from 0 (not at all) to 4 (extremely). The OCI-R has good psychometric properties: internal consistency for the full scale ranges from 0.81 to 0.93 , while test-retest reliability over a 2 -week period was reported as 0.71 to 0.91 for OCD patients. The OCI-R has also been shown to have good discriminant validity and good to excellent convergent validity [20]. As recommended by Foa et al. [20], we used a cutpoint of 18 for total OCI-R scores to identify participants with a clinical level of OCD symptoms.

\section{Methamphetamine Use Variables}

The frequency of methamphetamine use was measured as the number of days the participant used methamphetamine in the past 30 days ("During the past 30 days, on how many days did you do meth?"). A dichotomized variable was created using a median split, where scores greater than or equal to 11 (high frequency) were coded " 1 " and scores less than 11 (low frequency) were coded "0". Binge use of methamphetamine was assessed with a single question: "Are you a binge user? By binge user, we mean that you keep using large quantities of methamphetamine for a period of time, until you run out or just physically can't do it anymore." Responses were coded $1=$ yes, $0=$ no. 


\section{Sexual Risk Behaviors}

Sexual risk behavior was defined as unprotected sex with an opposite- or same-sex partner. For each sex partner, participants were asked how many times during the past 2 months they had engaged in anal, oral, and vaginal sex. A follow-up question was used to determine the number of times a condom or dental dam was used. A dichotomous variable was created to represent total number of sex acts during the previous 2 months. The distribution, which was positively skewed, was split at the second tertile so that a high score on number of sex acts was defined as $\geq 45$ sex acts and a low score was $<45$. In addition, two scales, each with three statements, were used to assess sexual risk behaviors associated with methamphetamine use. Response categories for all six statements ranged from 1 (Strongly Disagree) to 4 (Strongly Agree). The first three-item scale described vigorous sexual practices associated with methamphetamine use. The statements were: "When I'm high on meth: (a) I have sex until my genitals are raw, sore, or bleeding; (b) sex is so vigorous that condoms sometimes break or come off; and (c) oral sex is so intense that my partner sometimes gets cuts and tears in his/her mouth or penis." The alpha for this scale in the present sample was 0.72. The second set of three items described the pursuit of risky partners and risky sexual venues when high on methamphetamine: "When I'm high on meth: (a) I seek out risky sexual partners (e.g., anonymous partners, sex workers); (b) I go to places where I know I can get sex; and (c) I go cruising for sex partners at bookstores, parks or bars." Cronbach's alpha for this scale in the present sample was 0.79 . Dichotomized variables were created for each measure using a median split. For the vigorous sexual practices scale, scores greater than or equal to 2 (high risk behavior) were coded " 1 " and score less than 2 (low risk behavior) were coded "0". For the risky partners and risky venues scale, scores greater than or equal to 3 (high risk behavior) were coded "1" and scores less than 3 (low risk behavior) were coded " 0 ".

\section{Depressive Symptoms}

Depressive symptoms were assessed using the Beck Depression Inventory (BDI-II) [25]. The BDI-II comprises 21 items, each having four graded statements that are ordered (0-3) to show increasing depressive symptoms. Because somatic symptoms of depression can be confounded with physical symptoms and patients with HIV may be at higher risk for physical symptoms, we excluded the somatic items on the BDI-II and used only the 13-item cognitive-affective subscale in our analyses [26]. The sensitivity of this subscale to detect clinical depression has been demonstrated in previous studies [27]. Cronbach's alpha for the cognitive-affective subscale of the BDI-II in this sample was 0.92 , and scores ranged from 0 to 39 . For analytic purposes, a dichotomized variable was created using a median split where scores greater than or equal to 10 (higher depressive symptoms) were coded "1" and scores lower than 10 (lower depressive symptoms) were coded " 0 ".

\section{Statistical Analysis}

Since the total number of sex acts in the past 2 months yielded a positively skewed distribution, we corrected for skewness using a $\log 10+1$ transformation. A Kolmogorov-Smirnov test of normality [28] indicated that the transformed numberof-sex-acts variable approached a normal distribution $(p=0.971)$. A logistic regression analysis was used to identify correlates of clinical levels of OCD symptoms. Participants who scored 18 or more on the OCI-R were coded 1 (i.e., clinical level of OCD symptoms), and those who scored less than 18 were coded 0 (non-clinical level of OCD symptoms). Age was entered into the regression model as a control variable. Variables of interest were subsequently entered into the model simultaneously (i.e., number of days methamphetamine used in the past month, binge use of methamphetamine, cognitive-affective depressive symptoms, seek out risky venues and partners when "high" on methamphetamine, engage in vigorous sex when "high" on methamphetamine, and total number of sex acts in the past 2 months).

\section{Results}

\section{Sample Description}

By design, all participants were male. Participants were predominantly Caucasian (56.3\%), never married (84.1\%), living with another adult in a non-sexual relationship or living alone $(55.5 \%)$, unemployed $(82.4 \%)$, with a 2 -year degree or some college (44.9\%), and having an income of less than $\$ 10,000$ per year $(47.8 \%)$. The average age was 39.7 years $(\mathrm{SD}=7.7$, median $=40.0$, range $18-61$ ). Mean number of days that participants used methamphetamine in the past 30 days was 12.0 (SD $=9.0$, median $=10.0$, range 1-30). Forty-three percent of the sample self-identified as binge users of methamphetamine. Mean number of grams of methamphetamine used in the past 30 days was $9.5(\mathrm{SD}=16.9$, median $=3.5$, range 0.05-135). The mean number of sex acts in the past 2 months was $46.1(\mathrm{SD}=51.7$, median $=29.0$, range 2-300). The mean score on the cognitive-affective subscale of the BDI-II was 10.6 ( $\mathrm{SD}=8.3$, median $=10.0$, range 0-37). Sample characteristics are presented in Table 1. 
Table 1 Sample characteristics of HIV-positive methamphetamine-using MSM $(N=245)$

\begin{tabular}{|c|c|c|c|c|}
\hline Variable & $\begin{array}{l}\text { Clinical level } \\
\text { of OCD } \\
\text { symptoms }^{\mathrm{a}} \\
(N=64)\end{array}$ & $\begin{array}{l}\text { Non-clinical } \\
\text { level of OCD } \\
\text { symptoms }^{\text {b }} \\
(N=181)\end{array}$ & $\begin{array}{l}\text { Test } \\
\text { statistic }\end{array}$ & $\begin{array}{l}p \\
\text { value }\end{array}$ \\
\hline \multicolumn{5}{|l|}{ Background characteristics } \\
\hline Sexual orientation & & & $\chi^{2}=5.01$ & 0.171 \\
\hline Gay or homosexual & $76.6 \%$ & $82.3 \%$ & & \\
\hline Bisexual & 23.4 & 16.0 & & \\
\hline Not sure & 0.0 & 1.7 & & \\
\hline Ethnicity & & & $\chi^{2}=1.09$ & 0.780 \\
\hline Caucasian & $56.3 \%$ & $56.4 \%$ & & \\
\hline African American & 20.3 & 24.2 & & \\
\hline Latino & 14.0 & 13.3 & & \\
\hline Other & 9.4 & 6.1 & & \\
\hline Education & & & $\chi^{2}=5.83$ & 0.213 \\
\hline Less than high school & $20.3 \%$ & $9.4 \%$ & & \\
\hline High school or equivalent & 25.0 & 24.8 & & \\
\hline 2-Year degree or some college & 40.6 & 46.4 & & \\
\hline 4-Year college degree & 7.8 & 12.2 & & \\
\hline Graduate or advanced degree & 6.3 & 7.2 & & \\
\hline Marital status & & & $\chi^{2}=4.80$ & 0.187 \\
\hline Never married & $79.7 \%$ & $85.6 \%$ & & \\
\hline Married & 0.0 & 1.1 & & \\
\hline Separated & 3.1 & 5.0 & & \\
\hline Divorced & 17.2 & 8.3 & & \\
\hline Living arrangement & & & $\chi^{2}=34.36$ & 0.000 \\
\hline With same sex spouse or steady & $11.0 \%$ & $13.2 \%$ & & \\
\hline With opposite sex spouse or steady & 3.2 & 0.0 & & \\
\hline With other adults who are not sexual partners & 12.5 & 33.7 & & \\
\hline Alone & 20.3 & 29.9 & & \\
\hline Homeless & 29.6 & 7.7 & & \\
\hline Other & 23.4 & 15.5 & & \\
\hline Income & & & $\chi^{2}=3.52$ & 0.620 \\
\hline Less than $\$ 10,000$ & $51.6 \%$ & $46.4 \%$ & & \\
\hline$\$ 10,000-\$ 19,999$ & 35.8 & 38.7 & & \\
\hline$\$ 20,000-\$ 29,999$ & 1.6 & 6.6 & & \\
\hline$\$ 30,000-\$ 39,999$ & 4.7 & 2.8 & & \\
\hline$\$ 40,000-\$ 49,999$ & 1.6 & 2.2 & & \\
\hline$\$ 50,000$ or more & 4.7 & 3.3 & & \\
\hline Employed & $14.1 \%$ & $18.8 \%$ & $\chi^{2}=0.73$ & 0.258 \\
\hline Age (mean, SD) & $38.4(7.5)$ & $40.1(7.8)$ & $t=1.52$ & 0.130 \\
\hline Depression score (mean, SD) & $16.7(8.9)$ & $8.4(6.8)$ & $t=7.7$ & 0.000 \\
\hline \multicolumn{5}{|l|}{ Sexual and drug use behaviors } \\
\hline Binge use in past 2 months & $48.4 \%$ & $41.4 \%$ & $\chi^{2}=0.94$ & 0.204 \\
\hline $\begin{array}{l}\text { Number of grams of methamphetamine used } \\
\text { (mean, SD) }\end{array}$ & $8.8(12.3)$ & $9.2(18.0)$ & $t=0.162$ & 0.871 \\
\hline $\begin{array}{l}\text { Number of days methamphetamine used in past } \\
30 \text { days (mean, SD) }\end{array}$ & $13.3(10.6)$ & $9.8(8.7)$ & $t=2.4$ & 0.019 \\
\hline Number of sex acts in past 2 months (mean, SD) & 42.4 (47.6) & $47.4(53.1)$ & $t=0.46$ & 0.643 \\
\hline
\end{tabular}

a OCI-R score $\geq 18$

b OCI-R score $<18$

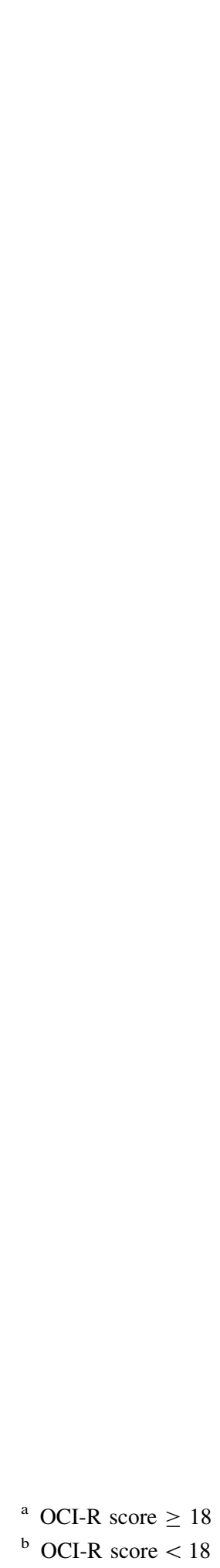




\section{OCD Prevalence}

The mean score on the 18-item OCI-R was 12.5 $(\mathrm{SD}=11.1$, median $=9.0$, range $0-51)$. Using the OCI-R cutpoint of 18 [20], 26.1\% of our sample met clinical criteria for OCD. We also examined participants' scores on subscales of the OCI-R (Table 2). The maximum score on each subscale is 12 . Washing, hoarding, and neutralizing were significantly correlated with greater frequency of methamphetamine use $(r=0.16,0.12,0.14$, respectively, $p<0.05)$. The obsessing, ordering, and checking subscales were not associated with methamphetamine use.

Factors Independently Associated with OCD

A single logistic regression analysis was performed to identify factors associated with clinical levels of OCD symptoms. Zero-order correlations among independent variables ranged from -0.28 to 0.21 . A test of the full model with seven predictors against a constant-only model was statistically significant $\left(\chi^{2}=50.2, p<0.001,-2\right.$ log likelihood $=230$ ). In our age-adjusted model, MSM with high depressive symptoms had more than five times the odds of having a clinical level of OCD symptoms compared with those who had low depressive symptoms. In addition, MSM who scored high on "seeking risky partners and venues when high on methamphetamine" had more than double the odds of a clinical level of OCD symptoms compared to those who scored low on this measure of sexual risk behavior. Interestingly, men who reported a high number of sexual acts in the past 2 months had a lower odds of a clinical level of OCD symptoms compared to those who reported a low number of sex acts during this time frame. Frequency of methamphetamine use, measured by number of days used in the past month, was also associated with OCD. Participants who scored high on frequency of methamphetamine use had a greater odds of having a clinical level of OCD symptoms compared to those who had low frequency of methamphetamine use (see Table 3).

Table 2 Mean, standard deviation, median and range for OCI-R subscales $(N=245)$

\begin{tabular}{lllll}
\hline OCI-R subscale & Mean & SD & Median & Range \\
\hline Washing & 1.37 & 1.87 & 1.00 & $0-11$ \\
Obsessing & 2.38 & 2.75 & 1.00 & $0-12$ \\
Hoarding & 2.69 & 2.42 & 2.00 & $0-11$ \\
Ordering & 2.78 & 2.75 & 2.00 & $0-12$ \\
Checking & 1.91 & 2.27 & 1.00 & $0-10$ \\
Neutralizing & 1.39 & 2.04 & 1.00 & $0-12$ \\
\hline
\end{tabular}

We conducted post hoc analyses to examine further the association between OCD symptoms and total number of sex acts, taking into account partner type and serostatus. $T$ test analyses yielded no differences in total number of sex acts by OCD group when examined separately by partner type (i.e., steady, casual, anonymous) or partner serostatus (i.e., HIV-negative, unknown serostatus, HIV-positive).

\section{Discussion}

In our sample of HIV-positive, methamphetamine-using MSM, clinical levels of OCD were associated with more frequent use of methamphetamine, more depressive symptoms, and more risky sexual behaviors when "high" on methamphetamine, but fewer sexual acts in a 2-month period. This profile suggests that efforts to treat methamphetamine use and promote safer sex practices in this target population may require efforts to mitigate and treat severe OCD symptoms.

Our finding that frequency of methamphetamine use was positively associated with OCD is consistent with the literature on OCD and substance use (e.g., [2, 29]). The clinical significance of the relationship between methamphetamine use and OCD may be that OCD patients who use stimulants have worse treatment outcomes. Brady et al. [30] described an OCD-like, compulsive foraging syndrome in cocaine-dependent individuals who in laboratory tests were obsessed with finding misplaced cocaine. Since this behavior has not been observed in persons with other drug addictions [31], it could be hypothesized that people who use stimulants and have severe OCD symptoms may not respond as well to conventional drug treatment programs. More research is needed to clarify the impact of the relationship between methamphetamine use and OCD on drug treatment outcomes.

Participants who met the threshold for a clinical level of OCD symptoms were also more likely to report seeking out risky sexual venues and risky sexual partners when "high" on methamphetamine. The novelty-seeking and exciting nature of risky sexual behaviors in the context of methamphetamine use may be reinforcing, thus making these behaviors more resistant to change. Accordingly, the effectiveness of sexual risk reduction programs may be enhanced by addressing OCD symptoms and teaching selfregulation techniques (e.g., cognitive reframing, delaying) that help individuals to manage their risky behaviors and their obsessions and compulsions. In addition, future studies should examine whether treatment for OCD is associated with reductions in sexual risk behaviors.

Contrary to expectation, total number of sex acts in the past 2 months was negatively associated with clinical levels of OCD symptoms. Although we cannot completely 
Table 3 Factors independently associated with obsessive-compulsive disorder in a sample of HIV-positive methamphetamine-using MSM $(N=243)$

\begin{tabular}{|c|c|c|}
\hline Variable & $\begin{array}{l}\text { Odds } \\
\text { ratio }\end{array}$ & $\begin{array}{l}95 \% \text { confidence } \\
\text { interval }\end{array}$ \\
\hline Age (per year increase) & 0.96 & $0.92-1.01$ \\
\hline Days per month of methamphetamine use (high frequency vs. low frequency) & 1.04 & $1.01-1.08$ \\
\hline Binge use of methamphetamine (vs. no binge use) & 0.72 & $0.36-1.42$ \\
\hline Cognitive-affective depressive symptoms (high distress vs. low distress) & 5.56 & $2.68-11.52$ \\
\hline Seek risky venues and partners when "high" on methamphetamine (high risk behavior vs. low risk behavior) & 2.57 & $1.22-5.43$ \\
\hline Engage in vigorous sex when "high" on methamphetamine (high risk behavior vs. low risk behavior) & 1.34 & $0.65-2.73$ \\
\hline Total number of sex acts in the past 2 months (high number of sex acts vs. low number of sex acts) & 0.33 & $0.15-0.72$ \\
\hline
\end{tabular}

Two cases missing data

rule out Type 1 error in these analyses, the bivariate correlation indicates that the relationship is truly inverse. A plausible explanation for our finding derives from the literature regarding sexual dysfunction and OCD. In a study that compared patients with OCD, major depressive disorder (MDD), and generalized anxiety disorder (GAD), Kendurkar and Kaur [32] reported that the rate of sexual dysfunction was $50 \%$ for OCD patients. As did MDD and GAD patients, OCD patients reported low sexual desire as the most common source of sexual dysfunction. Thus, it is not unreasonable to suggest that EDGE-II participants who met clinical criteria for OCD experienced low levels of sexual desire that was self-remedied by the use of methamphetamine. This hypothesis warrants attention in future studies.

Although this study focused on methamphetamine use and sexual risk behaviors as correlates of OCD, it was depressive symptoms, as measured by the cognitive-affective subscale of the BDI-II, that yielded the strongest relationship with OCD. This finding is consistent with previous research, which has demonstrated the co-occurrence of major depressive disorder and clinical levels of OCD [12, 13]. There is also evidence that depressed OCD patients have more severe OCD symptoms compared to those without comorbid depression $[14,15]$. From a clinical perspective, methamphetamine users who present with depressive symptoms should also be screened for OCD symptoms. Treatment programs that aim to reduce methamphetamine use and depression might combine psycho-pharmacological and psychotherapeutic treatments for OCD. A review of pharmacological therapies [33] concluded that administration of fluvoxamine or sertraline (two commonly used SSRIs) is the recommended treatment for OCD, with augmentation for refractory patients using risperidone, olanzapine, or quetiapine. The recommended psychotherapeutic treatment for OCD is cognitive behavioral therapy (CBT) [34]. CBT has been shown clinically effective with OCD patients using various methods of delivery, including individual, group, and telephone [35, 36].

A primary limitation of this study stems from its use of a convenience sample of HIV-positive, methamphetamineusing MSM who were volunteers in a sexual risk reduction intervention, since individuals who volunteer for research projects may not be representative of the larger target population. Another limitation stems from the self-report nature of the measures for OCD symptoms, methamphetamine use, and sexual risk behaviors. Self-report is subject to biases and inaccuracies in recall, particularly in relation to sexual and drug-use behaviors. This study is also limited by the use of a single question to measure binge use of methamphetamine. As noted by Lange and Voas [37], the concept of binging is inherently difficult to measure among substance users, which may explain the absence of multidimensional, standardized assessment tools. The singleitem measure used in this study appears to have face validity; however, future studies should explore the validity and reliability of this and other single-item measures. Although the OCI-R has been shown to discriminate between patients with OCD and anxious controls, sensitivity and specificity of the cutpoints should be examined in studies of patients with comorbid psychiatric disorders (e.g., depressive disorders). The cross-sectional nature of our data precludes us from making causal inferences regarding the association between methamphetamine use and OCD. Although some research has suggested that OCD symptoms precede substance use [1], it is also possible that methamphetamine use might induce OCD-like symptoms that may or may not be reversible. Prospective research designs are needed to address the issue of temporality to inform inferences about causality. Lastly, it is also possible that the relationship between methamphetamine use and OCD is explained by a confounding variable (e.g., co-use of other drugs, comorbid personality disorder) not considered in this research. 


\section{Concluding Remarks}

Overall, the present study suggests a need to increase health care professionals' awareness of OCD symptoms in methamphetamine users. Our findings also suggest that the combination of drug dependence, depressive symptoms, and OCD may be common in methamphetamine users. Future studies should seek to identify social, psychological, and behavioral factors as well as clinical consequences associated with this combination of morbidities.

Acknowledgments This research was funded by NIH R01 DA021115 (T.L. Patterson, P.I.). The authors thank Brian R. Kelly for assistance in editing the manuscript.

Open Access This article is distributed under the terms of the Creative Commons Attribution Noncommercial License which permits any noncommercial use, distribution, and reproduction in any medium, provided the original author(s) and source are credited.

\section{References}

1. Mancebo MC, Grant JE, Pinto A, Eisen JL, Rasmussen SA. Substance use disorders in an obsessive-compulsive disorder clinical sample. J Anxiety Disord. 2009;3(4):429-35.

2. Crum RM, Anthony JC. Cocaine use and other suspected risk factors for obsessive-compulsive disorder: a prospective study with data from the Epidemiologic Catchment Area surveys. Drug Alcohol Depend. 1993;31(3):281-95.

3. Semple SJ, Patterson TL, Grant I. Motivations associated with methamphetamine use among HIV + men who have sex with men. J Subst Abuse Treat. 2002;22:149-56.

4. Shoptaw S, Peck J, Reback CJ, Rotheram-Fuller E. Psychiatric and substance dependence comorbidities, sexually transmitted diseases, and risk behaviors among methamphetamine-dependent gay and bisexual men seeking outpatient drug abuse treatment. J Psychoactive Drugs. 2003;35(Suppl. 1):161-8.

5. Sallet PC, de Alvarenga PG, Ferrao Y, et al. Eating disorders in patients with obsessive-compulsive disorder: prevalence and clinical correlates. Int J Eat Disord. 2010;43(4):315-25.

6. Tamburrino MB, Kaufman R, Hertzer J. Eating disorder history in women with obsessive compulsive disorder. J Am Med Women's Assoc. 1994:49(1):24-6.

7. Corcos M, Nezelof S, Speranza M, et al. Psychoactive substance consumption in eating disorders. Eat Behav. 2001;2(1):27-38.

8. Abbey RD, Clopton JR, Humphreys JD. Obsessive-compulsive disorder and romantic functioning. J Clin Psychol. 2007;63(12): 1181-92.

9. Grant JE, Pinto A, Gunnip M, Mancebo MC, Eisen JL, Rasmussen SA. Sexual obsessions and clinical correlates in adults with obsessive-compulsive disorder. Compr Psychiatry. 2006;47(5):325-9.

10. Abramowitz JS, Storch EA, Keeley M, Cordell E. Obsessivecompulsive disorder with comorbid major depression: what is the role of cognitive factors? Behav Res Ther. 2007;45(10):2257-67.

11. McElroy SL, Phillips KA, Keck PE Jr. Obsessive compulsive spectrum disorder. J Clin Psychiatry. 1994;55(Suppl):33-51. Discussion 52-3.

12. Tukel R, Polat A, Ozdemir O, Aksut D, Turksoy N. Comorbid conditions in obsessive-compulsive disorder. Comprehen Psychiatry. 2002;43(3):204-9.
13. Overbeek T, Schruers K, Vermetten E, Griez E. Comorbidity and obsessive-compulsive disorder and depression: prevalence, symptom severity, and treatment effect. J Clin Psychiatry. 2002; 63(12):1106-12.

14. Hong J, Samuels J, Beinvenu OJ, et al. Clinical correlates of recurrent major depression in obsessive-compulsive disorder. Depress Anxiety. 2004;20:86-91.

15. Tukel R, Meteris H, Koyuncu A, Tecer A, Yazici O. The clinical impact of mood disorder comorbidity on obsessive-compulsive disorder. Eur Arch Psychiatry Clin Neurosci. 2006;256:240-5.

16. Guerrero AP, Hishinuma ES, Andrade NN, et al. Demographic and clinical characteristics of adolescents in Hawaii with obsessivecompulsive disorder. Arch Pediatr Adolesc Med. 2003;157(7): 665-70.

17. Fontenelle LF, Hasler G. The analytical epidemiology of obsessive-compulsive disorder: risk factors and correlates. Prog Neuropsychopharmacol Biol Psychiatry. 2008;32(1):1-15.

18. Grant JE, Mancebo MC, Pinto A, Williams KA, Eisen JL, Rasmussen SA. Late-onset obsessive-compulsive disorder: clinical characteristics and psychiatric comorbidity. Psychiatry Res. 2007;152(1):21-7.

19. Pinto A, Mancebo MC, Eisen JL, Paggano ME, Rasmussen SA. The Brown Longitudinal Obsessive Compulsivity Study: clinical features and symptoms of the sample at intake. J Clin Psychiatry. 2006;67(5):703-11.

20. Foa EB, Huppert JD, Leiberg S, et al. The Obsessive-Compulsive Inventory: development and validation of a short version. Psychol Assess. 2002;14(4):485-96.

21. Miller WR, Rollnick S. Motivational interviewing: preparing people to change addictive behavior. New York: The Guilford Press; 1991.

22. Bandura A. Social foundations of thought and action: a social cognitive theory. Englewood Cliffs: Prentice-Hall; 1986.

23. Beck AT, Rush AJ, Shaw BF, Emery G. Cognitive therapy of depression. New York: The Guilford Press; 1979.

24. Couper MP, Singer E, Tourangeau R. Automated self-interviewing and the survey measurement of sensitive behavior. In: Turner CF, Forsyth BH, O'Reilly J, et al., editors. Computerassisted survey information collection. New York: Wiley; 1998.

25. Beck AT, Steer RA, Brown GK. Beck depression inventory-II manual. San Antonio: Psychological Corporation; 1996.

26. Beck AT, Steer RA. Manual for the beck depression inventory. San Antonio: Psychological Corporation; 1993.

27. Clark DA, Steer RA. Use of nonsomatic symptoms to differentiate clinically depressed and nondepressed hospitalized patients with chronic medical illnesses. Psychol Rep. 1994;75:1089-90.

28. Schroeder KE, Carey MP, Vanable PA. Methodological challenges in research on sexual risk behavior. I. Item content, scaling, and data analytical options. Ann Behav Med. 2003;26: 76-103.

29. Fals-Stewart W, Schafer J. The treatment of substance abusers diagnosed with obsessive-compulsive disorder: an outcome study. J Subst Abuse Treat. 1992;9(4):365-70.

30. Brady KT, Lydiard RB, Malcolm R, Ballenger J. Cocaineinduced psychosis. J Clin Psychiatry. 1991;52:509-12.

31. Rosse RB, McCarthy MF, Alim TN, Deutsch SI. Saccadic distractibility in cocaine dependent patients: a preliminary laboratory exploration of the cocaine-OCD hypothesis. Drug Alcohol Depend. 1994;35:25-30.

32. Kendurkar A, Kaur B. Major depressive disorder, obsessivecompulsive disorder, and generalized anxiety disorder: do the sexual dysfunctions differ? Prim Care Companion J Clin Psychiatry. 2008;19(4):299-305.

33. Choi YJ. Efficacy of treatments for patients with obsessivecompulsive disorder: a systematic review. J Am Acad Nurse Pract. 2009;21(4):207-13. 
34. Ravindran AV, da Silva TL, Ravindran LN, Richter MA, Rector NA. Obsessive-compulsive spectrum disorders: a review of the evidence-based treatments. Can J Psychiatry. 2009;54(5):331-43.

35. Jonsson H, Hougaard E. Group cognitive behavioural therapy for obsessive-compulsive disorder: a systematic review and metaanalysis. Acta Psychiatr Scand. 2009;119(2):98-106.
36. Turner C, Heyman I, Futh A, Lovell K. A pilot study of telephone cognitive-behavioural therapy for obsessive-compulsive disorder in young people. Behav Cogn Psychother. 2009;37(4):469-74.

37. Lange JE, Voas RB. Defining binge drinking quantities through resulting BACs. Conf Proc Assoc Adv Automotive Med. 2000; 44:389-404. 